\title{
Biased Perceptions of Income Inequality and Redistribution
}

\author{
Carina Engelhardt* \\ University of Hannover
}

\author{
Andreas Wagener* \\ University of Hannover
}

\author{
Discussion Paper No. 526 \\ ISSN 0949-9962 \\ February 2014
}

\begin{abstract}
When based on perceived rather than on objective income distributions, the MeltzerRichards hypothesis and the POUM hypothesis work quite well empirically: there exists a positive link between perceived inequality or perceived upward mobility and the extent of redistribution in democratic regimes - though such a link does not exist when objective measures of inequality and social mobility are used. These observations highlight that political preferences and choices might depend more on perceptions than on factual data.
\end{abstract}

JEL Codes: H53, D72, D31

Keywords: Biased Perception, Majority Voting, Redistribution.

${ }^{*}$ Leibniz University of Hannover, School of Economics and Management, Koenigsworther Platz 1, 30167 Hannover, Germany. E-mail addresses: engelhardt@sopo.uni-hannover.de; wagener@ sopo.uni-hannover.de 


\section{Introduction}

The relationship between income inequality and redistribution in democracies is quite puzzling (Persson and Tabellini, 2000, p. 52). One seminal answer from a political-economy perspective is provided by Meltzer and Richard (1981) and Romer (1975), predicting that greater inequality of gross incomes leads to higher levels of redistribution in a majorityvoting equilibrium. Higher levels of inequality - measured by the ratio between mean and median gross incomes - imply that the politically decisive agent can gain more from, and consequently will demand for, more redistribution.

While theoretically convincing, the empirical performance of this prediction is mixed at best (see Section 2). This need not be surprising given that the Meltzer-Richard (henceforth: MR) model entails quite a long chain of logical steps from the ex-ante inequality in incomes to the extent of redistribution in a political equilibrium. The steps encompass, among others, the validity of the median voter hypothesis (actual policies are identical to the median voter's most preferred policy), the identity of median voter and median income earner, a purely materialistic and selfish attitude towards redistribution in a static framework, a direct link from voter preferences to policies etc.

This paper suggests a complementary explanation why empirical tests of the MR hypothesis often appear to be inconclusive or negative: they use objective income distributions rather than perceived ones. "Objective" refers to official statistics, which are meant to give an accurate decsription of a country's income distribution; "perceived" refers to how individuals view the income distribution and their position in it. There is ample of evidence (and we provide some, too) that individuals hold erroneous beliefs about income inequality, typically underestimate its extent and consider themselves to be relatively richer than they really are. If preferences for redistribution are based on perceived income inequality then less redistribution should emerge in a majority voting equilibrium, compared to the equilibrium predicted with the true income distribution. This follows from the comparative statics of the MR model. Moreover, since misperceptions of income inequality might differ across countries, the inequality ranking of countries based on perceived distributions may differ from that based on true data.

The idea that perceptions rather than facts and data drive redistributive politics is not restricted to the MR hypothesis but can also be applied to other theories. One particularly fruitful extension of the MR framework is provided by the Prospect of Upward Mobility (POUM) hypothesis. It posits that people with below average incomes today might not support redistribution because they believe that they or their children might move upward on the economic ladder in the future where progressive taxation will hurt them (Benabou and Ok, 2001). It is well established that citizens hold distorted (generally: too optimistic) expectations of (their) upward social mobility (Bjoernskov et al., 2013). Political preferences and policies formulated on the ground of these expectations will then differ from those based on factual data.

In this paper we first assess the MR hypothesis when based on perceptions of inequality. We use survey data from various waves of the International Social Survey Programme (ISSP) where individuals are asked to locate their own incomes on a range between 1 (poorest) 
and 10 (richest). From these self-assessments of incomes we construct a perceived distribution of incomes with an attending mean-to-median ratio. It turns out that these perceived ratios are, for all countries and years in our sample, considerably below their true values, indicating a widespread underestimation of income inequality. Employing these perceived inequality measures as explanatory variables for social expenditure, the MR hypothesis actually works quite fine empirically: a larger degree of perceived inequality indeed leads to a greater amount of redistribution. This observation survives all robustness checks to which we took it. Moreover, the stronger the misjudgement, i.e., the more benign the inequality situation is viewed relative to the objective one, the lesser are social expenditures.

In a second part, we also test a "perceived version" of the POUM hypothesis. We rely on the ISSP question that asks individuals how important (on a range from 1 to 5) they find hard work to get ahead. In line with the literature we interpret the assignment of a greater importance to hard work as an indicator for a greater perceived social mobility. As a factual measure of upward social mobility we use the share of people in the ISSP who report that they actually are in a higher occupation than their fathers. Regressing social expenditure on perceived and actual upward mobility, the former performs much better than the latter, both with respect to the sign of the effect and its statistical significance.

Section 2 embeds our study into the extant literature. Section 3 presents our work on the MR hypothesis, describing data and methodology, results, and robustness checks. Section 4 does the same for the POUM hypothesis. Section 5 concludes. The Appendix collects information on data sources, variable definitions and supplementary regressions and further robustnees checks.

\section{Related observations}

Previous research by economists and political scientists tried to confirm the Meltzer and Richard (1981) model empirically, but the resulting evidence is mixed. Some studies find the hypothesized positive link between inequality and redistribution (see, e.g., Borge and Rattsoe, 2004; Finseraas, 2009; Mahler, 2008; Meltzer and Richard, 1983; Milanovic, 2000), while others suggest a negative relationship (e.g., Georgiadis and Manning, 2012; Rodrìguez, 1999) or no significant link at all (e.g., Gouveia and Masia, 1998; Kenworthy and McCall, 2008; Pontusson and Rueda, 2010; Scervini, 2012).

These studies differ in what they use as their measure of incomce inequality (the ratio of mean to median income, the Gini coefficient, the income share of the $1 \%$ richest etc.). However, they all evaluate their inequality measures with "objective" data from statistical offices, OECD, LIS, or tax authorities. These data and the picture of inequality they portray need not coincide with how citizens and voters themselves perceive the income distribution.

There are good reasons to assume that citizens hold distorted views on inequality. Experiments show that respondents fail to determine their own position in the income scale (Cruces et al., 2013). Furthermore, they underestimate income inequality per se. Norton and Ariely (2011) observe considerable discrepancies between actual and perceived levels of inequality 
in wealth in the U.S.: citizens view the wealth distribution vastly more equal than it actually is. Similarly, Osberg and Smeeding (2006) show that estimated disparities between the earnings of different occupational groups are much smaller than actual differences, suggesting again an underestimation of income inequality. Bartels $(2005,2008)$ argues that knowledge about inequality in the U.S. is not only low but also shaped by political ideology, with conservatives [liberals] being less [more] aware of the rising inequality, even after controlling for their level of general political knowledge.

Sociologists have since long estabished that individuals systematically underestimate the real extent of inequality. This oocurs mainly due to the failure to locate their own position in the income distribution. Several reasons may account for this phenomenon, ranging from limited availability of social comparisons - which leads individuals to falsely believe that they are close to the average income earner (Evans and Kelley, 2004; Runciman, 1966) - to so-called self-enhancement biases - individuals are inclined to see their own (income) position rosier and relatively better than it actually is (generally see, e.g., Guenther and Alicke, 2010). These misperceptions generally invoke an underestimation of (income) inequality. Inequality is not the only economically relevant variable that is subject to biased perceptions. Substantial evidence, both empirical and experimental, shows that individuals hold distorted perceptions of risks, tax burdens and rates - and of social mobility (Bjoernskov et al., 2013). This latter aspect is relevant especially for the POUM hypothesis.

In that spirit, political and social scientists have recently started to substitute actual by perceived inequality in their studies. But their measures of perceived inequality so far are questionable. E.g., the frequently used measure of perceived wage inequality from the ISSP entails a personal evaluation of the degree of inequality but does not take into account potential biases from incorrect self-positioning, which we just assume to be an important factor.

Rather than actual redistributive policies (typically measured by social expenditure in percent of GDP etc.), one can also correlate individual preferences ("demand") for redistribution with income inequality. For the MR hypothesis, the performance of such studies is typically better than of social quota-studies, indicating that individuals in more unequal societies would opt for more redistribution through the state. However, preference for redistribution might be regarded as a mere cheap-talk, individual statement of inequality aversion; the link from voter preferences to actual policies is still lacking (and, at least for the MR hypothesis, seems to be broken). A direct test of the MR hypothesis should use policy outcomes as dependent variables.

Bredemeier (2014) theoretically discusses those determinants of rising inequality that can account for a lower demand for redistribution. The paper argues that when the income of the poor increases, the perceived inequality decreases (even though the mean-to-median ratio might actually increase) and the demand for redistribution goes down. This supports our hypothesis that political outcomes based on expectations will differ from those based on factual data.

The POUM hypothesis has mainly been tested with respect to preferences for redistribution. For both the degrees of perceived social mobility (based on the hard-work question) and of experienced social mobility (based on the comparison to one's father's job) Corneo and Grüner (2002) show that they weaken support for the statement that governments 
should reduce inequalities. However, this is again more a statement on inequality aversion than on political outcomes. The dependent variable in Alesina and La Ferrara (2005) is more specific (agreement with the statement that "the government should reduce income differences between the rich and the poor"). Interestingly, in this study all measures of "perceived" social mobility are negatively correlated with the support of more redistribution - while most measures of experienced upward mobility show no association with the desire for larger social spending. In Section 4 we will show that this also holds for actual (rather than desired) redistribution.

\section{The MR hypothesis and perceived inequality}

\subsection{Data and descriptive statistics}

The ISSP provides the best available comparative data on public opinion regarding inequality and redistribution (Brooks and Manza, 2006; Kenworthy and McCall, 2008; Lübker, 2006; Osberg and Smeeding, 2006). Using the ISSP, we design a measure of perceived inequality in the income distribution. This measure is based on the following survey question:

"In our society there are groups which tend to be towards the top and groups which tend to be toward the bottom. Below is a scale that runs from top to bottom (horizontal scale (10 top - 1 bottom)). Where would you put yourself now on this scale?"

Data on the answers are available for the years 1987, 1992, 1999 and 2006-2009 for 26 OECD countries covered on the ISSP. ${ }^{1}$ Because we assume inequality to have an influence on social expenditures, 5 waves were defined in such a way that inequality measures and slightly delayed social expenditures are merged ${ }^{2}$.

We assume that self-assessments are mainly made in terms of income, and thus, provide an approximation of the perceived position in the income distribution. The histograms (relative frequencies) for the average answers to the question above are depicted country-by-country in Figure 1.

The distributions in Figure 1 exhibit a remarkable degree of symmetry (sometimes even leftskewedness). Compared to the stark right-skewedness of actual income distributions this indicates that the inequality situation might be misperceived by the public. This is in line with two common results from studies on inequality perception: that individuals tend to see themselves farther to the right of the income distribution than they actually are and that they conceive the distribution as more bell-shaped than it actually is.

\footnotetext{
${ }^{1}$ These are: Austria, Belgium, Canada, Switzerland, Chile, Czech Republic, Germany, Denmark, Spain, Finland, France, UK, Ireland, Italy, Japan, South Korea, Mexico, the Netherlands, Norway, New Zealand, Poland, Portugal, Sweden, Slovenia, Turkey, and the US.

${ }^{2} \mathrm{We}$ do so in section 4 , too.
} 


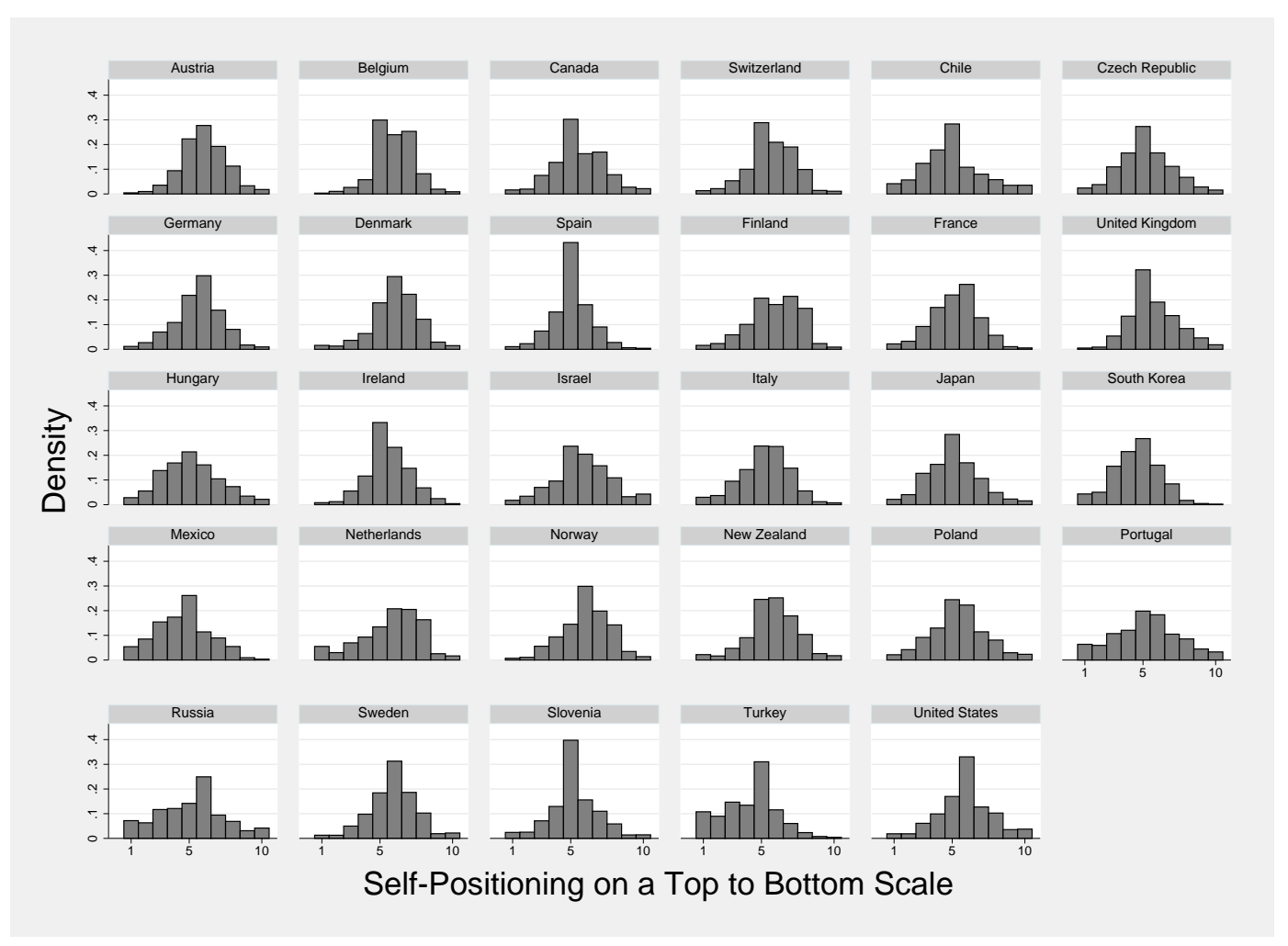

Figure 1: Generated income distribution by country.

To make sure, the hypothetical income distributions in Figure 1 are based on the aggregation of individual and categorical data. Thus, they are not perceptions of the income distribution that any specific individual in society holds but rather a summary view on how society categorizes itself with respect to inequality.

We next calculate the average and the median value of the self-categorizations as well as their ratio. We call this ratio the "perceived" mean-to-median ratio. To capture that (mis)perceptions of inequality can be expected to be larger the more unequal a country actually is, we also construct an additional measure for perceived inequality (called "weighted perception") by dividing perceived mean-to-median ratios by the factual ones:

$$
\text { weighted perception }:=\frac{\text { mean-to-median (perceived) }}{\text { mean-to-median (OECD) }}
$$

Table 1 reports the actual mean-to-median value (calculated from OECD statistics), the perceived one and the measure for weighted perceived inequality. Actual mean-to-median ratios are uniformaly greater than perceived ones, indicating that inequality is underestimated everywhere. Weighted perceived inequality ranges from 0.986 to 0.594 , evidencing that the inequality is frequently underestimated to a very considerable degree. The figures are based on cross-sectional data. Table 5 in the Appendix shows the weighted perceived inequality measure per wave, indicating a widespread underestimation of inequality in each period. 
Table 1: Mean-to-Median Ratio and Misjudgment

\begin{tabular}{lccc}
\hline & official & perceived & weighted perception \\
\hline Austria & 1.116 & 1.065 & 0.954 \\
Belgium & 1.088 & 0.993 & 0.912 \\
Canada & 1.141 & 1.022 & 0.895 \\
Chile & 1.656 & 0.984 & 0.594 \\
Czech Republic & 1.132 & 1.076 & 0.951 \\
Denmark & 1.055 & 1.004 & 0.949 \\
Finland & 1.080 & 0.986 & 0.914 \\
France & 1.159 & 1.003 & 0.865 \\
Germany & 1.131 & 1.039 & 0.919 \\
Ireland & 1.170 & 1.066 & 0.912 \\
Italy & 1.138 & 1.003 & 0.881 \\
Japan & 1.144 & 0.985 & 0.861 \\
Mexico & 1.526 & 0.912 & 0.598 \\
Netherlands & 1.156 & 0.966 & 0.836 \\
New Zealand & 1.178 & 1.010 & 0.857 \\
Norway & 1.077 & 1.017 & 0.945 \\
Poland & 1.171 & 1.036 & 0.885 \\
Portugal & 1.265 & 1.099 & 0.869 \\
Slovenia & 1.077 & 1.063 & 0.986 \\
South Korea & 1.105 & 0.912 & 0.825 \\
Spain & 1.137 & 1.046 & 0.920 \\
Sweden & 1.078 & 1.023 & 0.949 \\
Switzerland & 1.149 & 1.030 & 0.956 \\
Turkey & 1.411 & 0.847 & 0.600 \\
UK & 1.210 & 1.141 & 0.944 \\
US & 1.192 & 1.043 & 0.875 \\
\hline
\end{tabular}




\subsection{Empirical results}

Figure 2 provides a first insight into the relationship of social spending ${ }^{3}$ and the different inequality measures. Plotting social expenditures (in percent of GDP) against actual and perceived inequality in different countries, it shows a negative correlation between social expenditures and factual inequality (left panel) and on the other hand a (positive) association between social expenditure and the perceived inequality (middle and right panel). In this
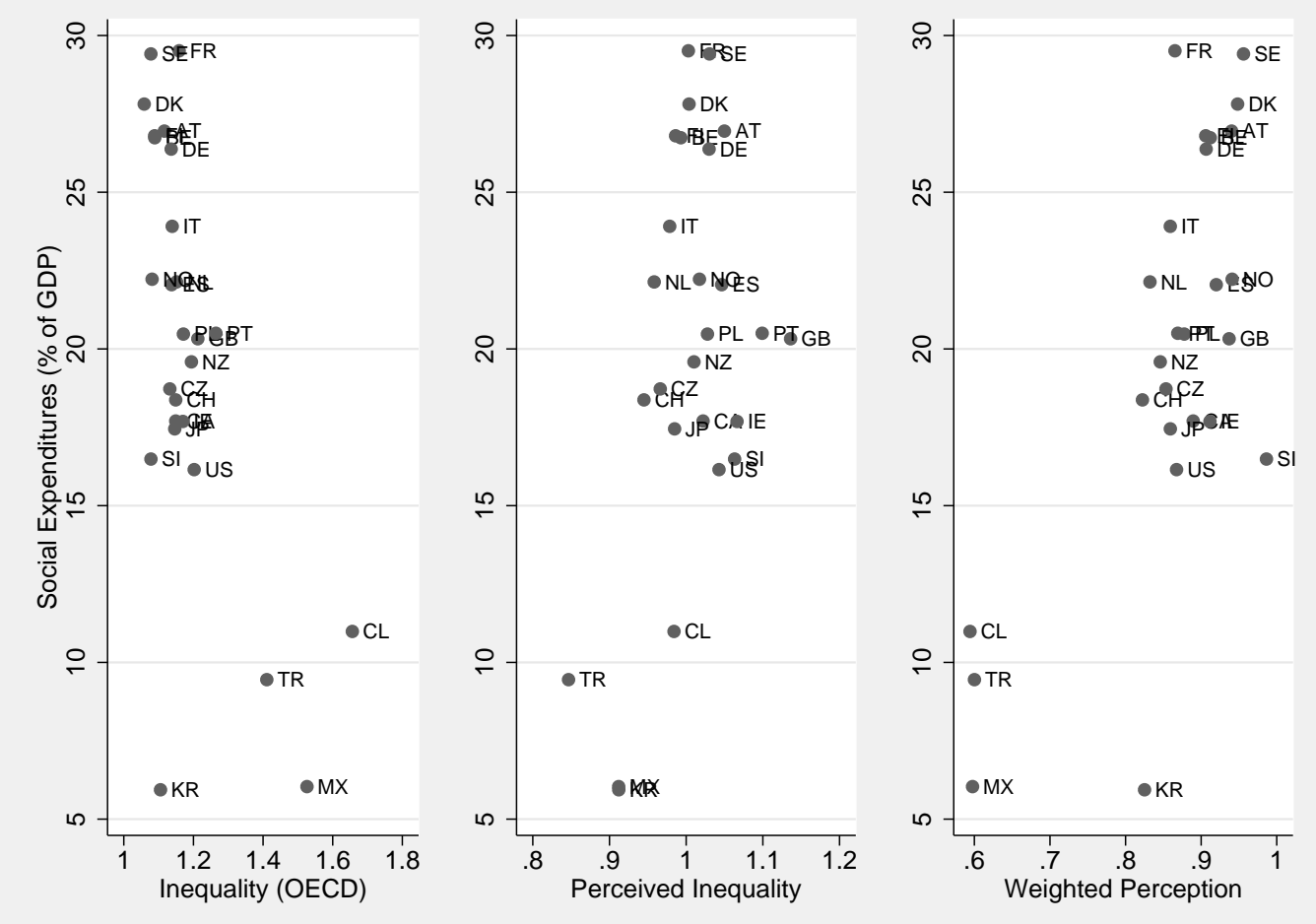

Figure 2: Misjudgment and social expenditures

figure cross-sectional data are used. We also checked if these correlations hold for each individual time period.

Table 2 provides statistical evidence on these correlations. Panel A reports the results from regressing, in various specifications, social expenditures (in percent of GDP) on actual income inequality, i.e., on the ratio of mean to median income based on official OECD statistics. Specification (1) is the simple regression between actual inequality and social spending, while regressions (2) to (5) include as additional regressors ${ }^{4}$ the current GDP (to capture the positive income elasticity of social spending), an indicator for openness and the dependency ratio (both to capture the necessity for social spending) and social expenditure in the 1980s to capture path-dependence of social spending. Column (3) is the same as column (1) with the 1987 data omitted, which are included in columns (4) and (5) as independent variables. Contrary to what the MR hypothesis predicts - but similar to what others studies found as

\footnotetext{
${ }^{3}$ Data source: OECD iLibrary.

${ }^{4}$ Data source: OECD iLibrary, too.
} 
well -, the correlation between actual inequality and social spending is always significantly negative, suggesting that lower inequality fosters redistribution.

Panel B of Table 2 reports our results from regressing, again in the same sequence of specifications as before, social expenditures (as a percentage of GDP) on perceived income inequality, as measured by the ratio of mean income to median income in the distributions imputed from the answers in the ISSP. The correlation between inequality and social expenditure now turns out to be positive, as predicted by the MR hypothesis. In all but the last specification, the coefficient is statistically significant (and even the insignificant coefficient in the last column is better in line with the theory than the corresponding negative one in Panel A). In essence, using perceived rather than actual inequality leads to a better performance of the MR hypothesis.

Panel C of Table 2 finally reports regressions of social expenditure on the weighted perception of the inequality situation. Coefficients of weighted perceptions are highly statistically significant in all specifications and substantiate the positive relationship. As argued before, present information on inequality (country) cluster might influence inequality evaluation. Our regressions strongly support this view, across all specifications.

Across all panels in Table 2 all statistically significant control variables show the expected signs; only specification (5) leads to an unexpected negative coefficient of per-capita GDP.

In view of well-known endogeneity issues, regressions of social spending on other variables should be interpreted cautiously. We cannot fully resolve, but try to capture them by including lagged social spending as an independent variable. This decreases the absolute size of all coefficients of the inequality measures (see columns (4) and (5) in Table 2) - but does not change the apparent difference in signs. Hence, we refrain from interpreting the size of coefficients. Nevertheless, our results show that it is important to differentiate between factual and perceived inequality.

\subsection{Robustness checks}

We subject our analysis to a variety of robustness checks, none of which qualitatively affects our general conclusion. First, measuring the degree of redistribution by social expenditures per capita (rather than by a percentage of GDP) again produces a positive link between perceived inequality and redistribution (see Table 6 in the Appendix).

We also included variables that previous studies found to be imporant drivers for (a preference for) more redistribution. These include religious attendance, trust, and ideology (left/right). Quantitative measures for these variables can be obtained from the World Values Surveys. The results reported in Panels A and B of Table 7 in the Appendix show that, while statistically insignificant jointly, a more leftist attitude, a lower degree of trust and more frequent religious attendance go along with increased redistribution (the latter only insignificantly). The association between social spending and inequality measures remains unaffected, though.

As can be seen in Figure 2 Mexico, Turkey, South Korea and Chile are outlier in our data set. 


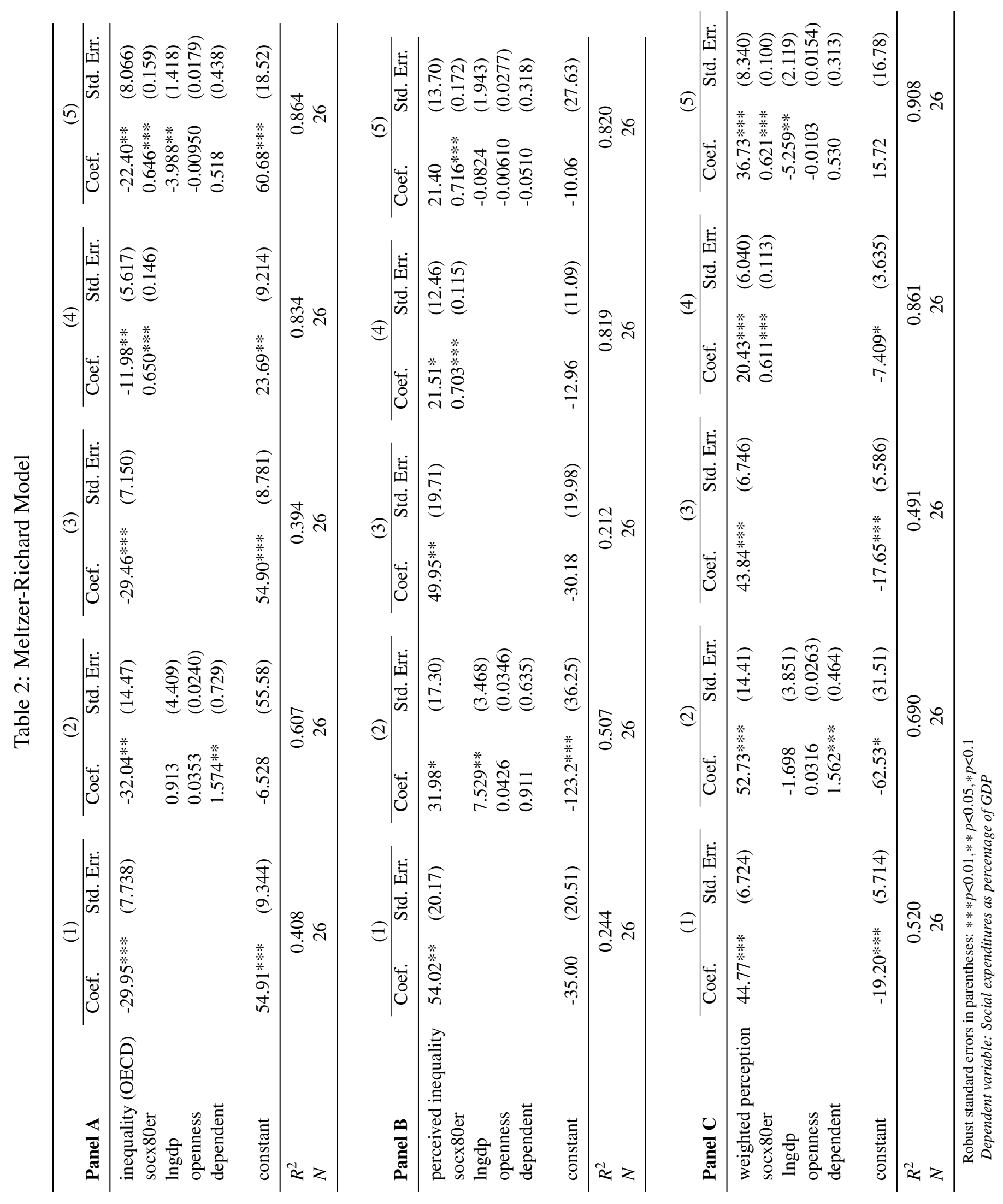


To rule out that statistical significance is driven by these countries, we run regressions again and exclude them. This does not alter statistical significance in a remarkable degree ${ }^{5}$.

\section{The POUM hypothesis and perceived social mobility}

\subsection{Perceived vs. experienced social mobility}

The POUM hypothesis posits that redistribution by the government is lower in democracies the higher is the degree of upward moility. As for the MR hypothesis in the previous section, we again argue that distinguishing between perceived and actual mobility is of crucial importance.

The ISSP provides data that can be used to measure experienced (= actual) as well as perceived social upward mobility. A widely used measure of experienced mobility is based on the following survey question:

"Please think about your present job (or your last one if you don't have one now). If you compare this job to the job your father had when you were $14,15,16$, would you say that the level of status of your job is (or was)... 1. Much lower than your father's, 2. Lower, 3. About equal, 4. Higher or 5. Much higher than your father's?"

The share of respondents who give answers 4 or 5 (i.e., the fraction of people who think they moved ahead of their fathers in their occupations) can serve as a measure of experienced mobility in a society can be calculated as the share in a higher occupation as one's father. ${ }^{6}$

A common measure of expected or perceived upward mobility is based on the hard-work question:

"Please tick one box to show how important you think hard work is for getting ahead in life (1 - not important at all; 5 - essential)."

Higher numbers indicate a stronger perception that social structures are permeable and allow for upward mobility. For sake of comparability, we normalized this measure to the unit interval, measuring the average importance of hard work for getting ahead.

Table 3 reports the average values of experienced and expected mobility in our sample. The sample covers the years in 1992, 1999 and 2009 for 24 OECD countries covered in the ISSP. ${ }^{7}$

\footnotetext{
${ }^{5}$ Essentially, regressions using the simple perceived inequality measure lose statistical significance.

${ }^{6}$ We exclude all people who have never had a job or who do not know what their father did, never knew their father or whose father never had a job.

${ }^{7}$ These are: Austria, Canada, Chile, Czech Republic, Denmark, Finland, France, Germany, Hungary, Italy, Israel, Japan, New Zealand, Norway, Poland, Portugal, Sweden, Slovenia, South Korea, Spain, Switzerland, Turkey, UK, and the US.
} 
Figures per year are shown in Table 8 in the appendix. As can be seen from column 1, the likelihood of being in a higher occupation than one's father ranges from 0.212 in Japan to 0.552 in France. Column (2) shows values of perceived mobility which range between 0.638 and 0.858 . Thus, people believe in the importance of hard work to get ahead and therefore in social mobility.

Table 3: Upward mobility

\begin{tabular}{lcc}
\hline & $\begin{array}{c}(1) \\
\text { experienced }\end{array}$ & $\begin{array}{c}(2) \\
\text { perceived }\end{array}$ \\
\hline Austria & 0.436 & 0.721 \\
Canada & 0.501 & 0.740 \\
Chile & 0.358 & 0.669 \\
Czech Republic & 0.362 & 0.638 \\
Denmark & 0.468 & 0.681 \\
Finland & 0.482 & 0.744 \\
France & 0.552 & 0.629 \\
Germany & 0.420 & 0.696 \\
Hungary & 0.411 & 0.646 \\
Italy & 0.524 & 0.730 \\
Israel & 0.482 & 0.677 \\
Japan & 0.212 & 0.703 \\
New Zealand & 0.438 & 0.784 \\
Norway & 0.420 & 0.726 \\
Poland & 0.504 & 0.724 \\
Portugal & 0.600 & 0.703 \\
Slovenia & 0.389 & 0.649 \\
South Korea & 0.377 & 0.858 \\
Spain & 0.523 & 0.675 \\
Sweden & 0.391 & 0.718 \\
Switzerland & 0.466 & 0.761 \\
Turkey & 0.353 & 0.798 \\
UK & 0.496 & 0.727 \\
US & 0.500 & 0.816 \\
\hline
\end{tabular}

\subsection{Empirical results}

Figure 3 visualizes a (positive) association between social expenditures (in percent of GDP) and experienced upward mobility as well as a (negative) correlation between social spending and perceived upward mobility. The contrast in directions is similar to what we encountered for the MR hypothesis.

Again, cross-sectional data are used in this figure and we checked if these correlations hold for each individual time period, too.

The regressions reported in Table 4 confirm the prima facie evidence of Figure 3. Regressions for experienced mobility (Panel A) indicate - if anything - a weakly positive correlation between redistribution and social mobility, contradicting the POUM hypothesis. Moreover, except for the simple regression of column (1), the results are statistically insignificant. By contrast, using perceived mobility fully vindicates the POUM hypothesis (see Panel B in 

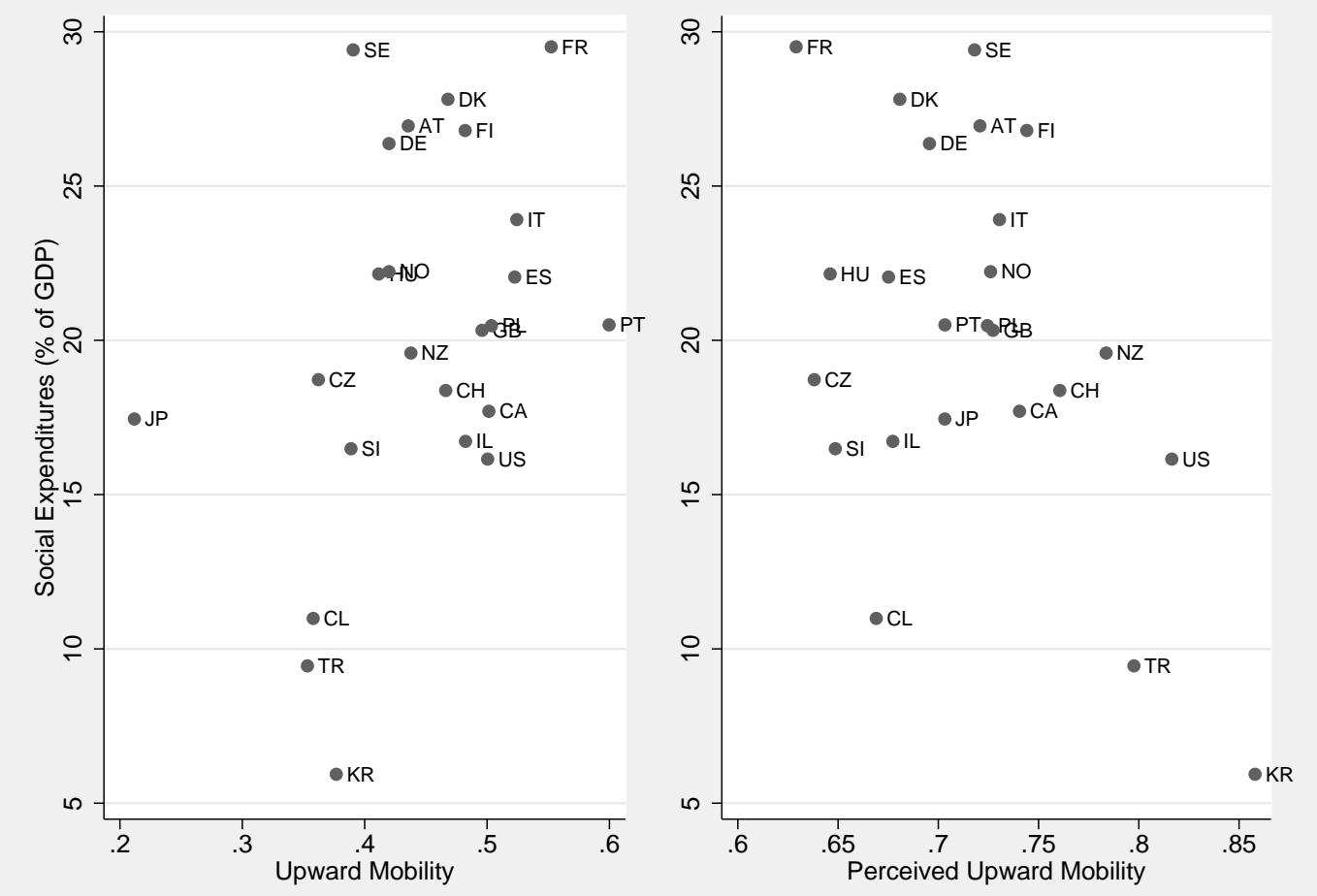

Figure 3: Redistribution and upward mobility

Table 4) in a statistically significant way. These observations are invariant across the various specifications, which follow the pattern of the previous section (cf. columns (1) to (4)).

\subsection{Robustness checks}

Again, we subjected our analysis to various robustness checks. First, we re-defined the measure of experienced mobility by calculating the probability of being in a much better occupation than one's father; see Table 9. This more restrictive definition does not alter our general conclusion - but it renders all results based on experienced mobility statistically significant (cf. Panel A in Table 9).

Although the "hard-work question" is widely used in the literature, it need not perfectly reflect expected upward mobility: even if someone believes that social mobility is low he could convinced of the importance of hard work for getting ahead. Therefore, we experiment with a measure for perceived immobility: it takes a value of one if the respondent states that hard work is not important at all to get ahead. If a respondent state that hard work is totally unimportant we can assume that he does not believe in upward mobility. In line with the POUM hypothesis we would therefore expect that social spending increases with higher perceived social immobility, measured by the population average. As can be seen in Table 9, this in fact holds empirically. 


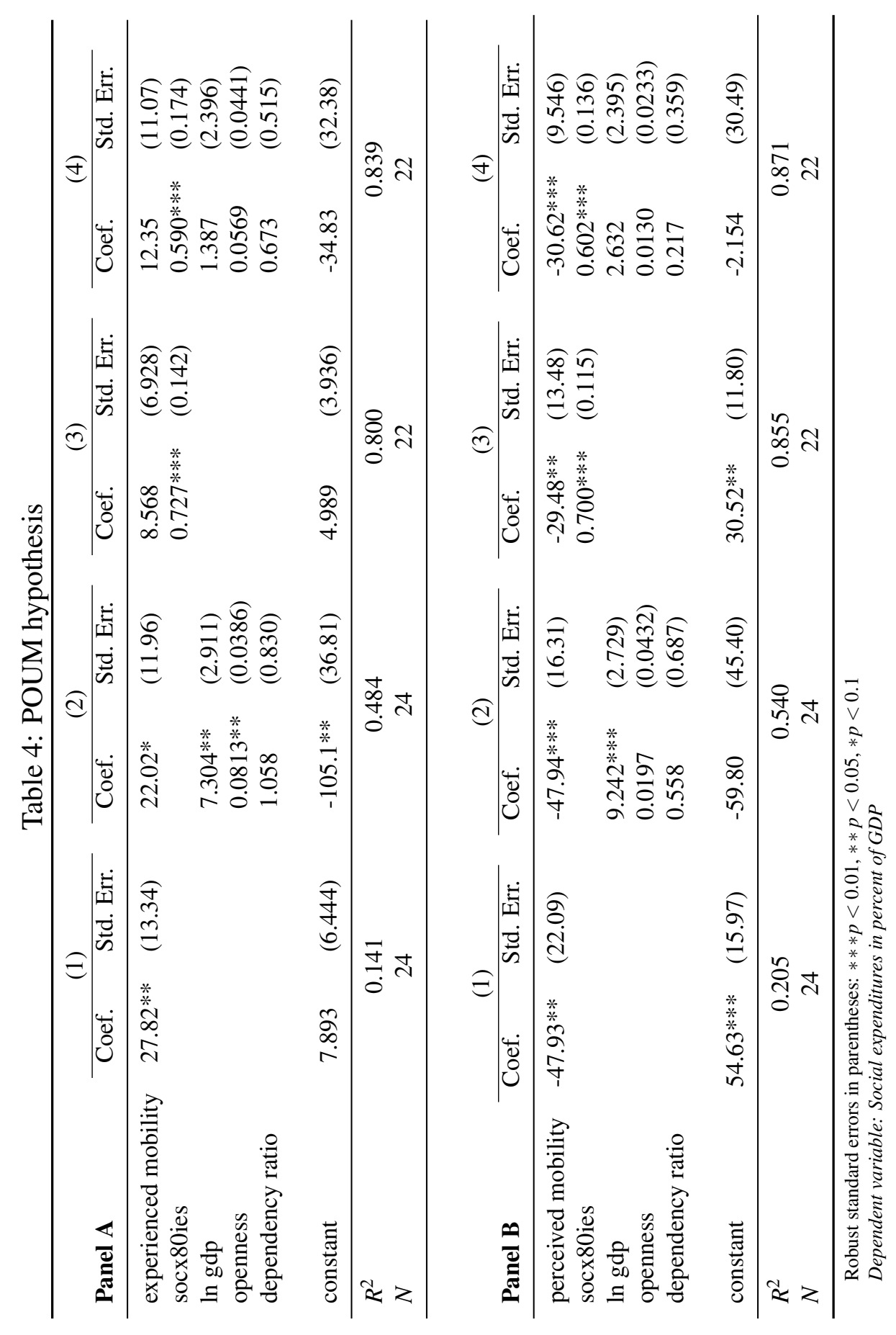


Table 10 in the Appendix demonstrates that controlling for political and religious attitudes corroborates our findings: Panel A confirms that redistribution is lower the higher is actual social mobility (thus, questioning the POUM hypothesis) while Panel B evidences a negative correlation between perceived mobility and social expenditure.

\section{Concluding remarks}

In democratic political systems, the perceptions of the electorate on issues matter. In fact, perceptions might matter more than objective data. If citizen-voters see an issue, politics has to respond - even if there is no issue; conversely, if a (real) problem is not salient with voters, it will probably not be pursued forcefully.

This idea can be applied to "populist" politics of progressive tax-transfer problems. Our study suggests that perceived inequality and expected upwards mobility are good predictors of social policy, sometimes even better ones than objective, offical or factual measures. As a first attempt to trace social expenditures back to perceptions of inequality, our results are preliminary but open directions for future research. First, to check the stability of our oberservation it will be interesting to repeat some of the empirical studies that test the MR or the POUM hypothesis with official measures for inequality or social mobility with perceived measures. Second, changing the dependent variable from actual social spending to preferences for redistribution will show whether perceptions also matter for voters' wishes. Third, while our study takes perceptions as exogenous, one could study how these perceptions are shaped. This could then give rise to a more complete understanding of political choices in democracies. Finally, the discrepancies between perceptions and actual data might also matter for policy areas other than social spending. 


\section{References}

Alesina, A., La Ferrara, E., 2005. Preferences for redistribution in the land of opportunities. Journal of Public Economics 89, 897-931.

Bartels, L. M., 2005. Homer gets a tax cut: Inequality and public policy in the American mind. Perspectives on Politics 3, 15-31.

Bartels, L. M., 2008. Unequal Democracy: The Political Economy of the New Gilded Age. Princeton University Press, Princeton, NJ.

Benabou, R., Ok, E. A., 2001. Social mobility and the demand for redistribution: The POUM hypothesis. Quarterly Journal of Economics 116, 447-487.

Bjoernskov, C., Dreher, A., Fischer, J. A., Schnellenbach, J., Gehring, K., 2013. Inequality and happiness: When perceived social mobility and economic reality do not match. Journal of Economic Behavior and Organization 91, 75-92.

Borge, L.-E., Rattsoe, J., 2004. Income distribution and tax structure: Empirical test of the Meltzer-Richard hypothesis. European Economic Review 48, 805-826.

Bredemeier, C., 2014. Imperfect information and the Meltzer-Richard hypothesis. Public Choice (forthcoming).

Brooks, C., Manza, J., 2006. Social policy responsiveness in developed democracies. American Sociological Review 71, 474-494.

Corneo, G., Grüner, H.-P., 2002. Individual preferences for political redistribution. Journal of Public Economics 83, 83-107.

Cruces, G., Perez-Truglia, R., Tetaz, M., 2013. Biased perception of income distribution and preferences for redistribution: Evidence from a survey experiment. Journal of Public Economics 98, 100-112.

Evans, M., Kelley, J., 2004. Subjective social location: Data from 21 nations. International Journal of Public Opinion Research 16, 3-38.

Finseraas, H., 2009. Income inequality and demand for redistribution: A multilevel analysis of European public opinion. Scandinavian Political Studies 32 (1), 94-119.

Georgiadis, A., Manning, A., 2012. Spend it like Beckham? Inequality and redistribution in the UK, 1983-2004. Public Choice 151, 537-563.

Gouveia, M., Masia, N. A., 1998. Does the median voter model explain the size of government? evidence from the States. Public Choice 97, 159-177.

Guenther, C. L., Alicke, M. D., 2010. Deconstructing the Better-than-Average effect. Journal of Personality and Social Psychology 99, 755-770.

Kenworthy, L., McCall, L., 2008. Inequality, public opinion and redistribution. SocioEconomic Review 6, 35-68. 
Lübker, M., 2006. Inequality and the demand for redistribution: Are assumptions of the new growth theory valid? Socio-Economic Review 5, 117-148.

Mahler, V. A., 2008. Electoral turnout and income redistribution by the state: A crossnational analysis of developed democracies. European Journal of Political Research 47, $161-183$

Meltzer, A. H., Richard, S. F., 1981. A rational theory of the size of government. The Journal of Political Economy 89 (5), 914-927.

Meltzer, A. H., Richard, S. F., 1983. Tests of a rational theory of the size of government. Public Choice 41 (3), 403-418.

Milanovic, B., 2000. The median-voter hypothesis, income inequality, and income redistribution: An empirical test with the required data. European Journal of Political Economy $16(3), 367-410$.

Norton, M. I., Ariely, D., 2011. Building a better America - one wealth quintile at a time. Perspectives on Psychological Science 6, 9-12.

Osberg, L., Smeeding, T., 2006. "Fair" inequality? attitudes toward pay differentials: The United States in comparative perspective. American Sociological Review 71, 450-473.

Persson, T., Tabellini, G., 2000. Political Economics: Explaining Economic Policy. The MIT Press, Cambridge, MA.

Pontusson, J., Rueda, D., 2010. The politics of inequality: Voter mobilization and left parties in advances industrial states. Comparative Political Studies 43, 675-705.

Rodrìguez, F. C., 1999. Does distributional skewness lead to redistribution? evidence from the United States. Economics and Politics 11 (2), 171-199.

Romer, T., 1975. Individual welfare, majority voting and the properties of a linear income tax. Journal of Public Economics 4 (2), 163-185.

Runciman, W. G., 1966. Relative Deprivation and Social Justice: A Study of Attitudes to Social Inequality in Twentieth-Century England. Routledge Kegan Paul, London.

Scervini, F., 2012. Empirics of the median voter: Democracy, redistribution and the role of the middle class. Journal of Economic Inequality 10, 529-550. 


\section{Appendix}

Addenda to Section 3 (Meltzer-Richard Model)

Table 5: Weighted perception per year

\begin{tabular}{lccccc}
\hline & $(1)$ & $(2)$ & $(3)$ & $(4)$ & $(5)$ \\
& 1987 & 1992 & 1999 & $2006 / 07$ & $2008 / 09$ \\
\hline Austria & & & 0.954 & 0.950 & 0.921 \\
Belgium & & & & 0.912 & \\
Canada & & 0.919 & 0.900 & 0.854 & \\
Chile & & & & 0.537 & 0.633 \\
Czech Republic & & & 0.924 & 0.795 & 0.834 \\
Denmark & & & & & 0.940 \\
Finland & & & & 0.887 & 0.920 \\
France & & & 0.965 & 0.819 & 0.797 \\
Germany & 0.969 & 0.991 & 1.000 & 0.803 & 0.835 \\
Ireland & & & & 0.899 & 0.902 \\
Italy & & 0.912 & & & 0.835 \\
Japan & & & 0.932 & 0.828 & 0.816 \\
Mexico & & & & 0.616 & \\
Netherlands & 0.831 & & & & 0.838 \\
New Zealand & & 0.837 & 0.889 & 0.820 & 0.837 \\
Norway & & 0.966 & 0.894 & 0.987 & 0.918 \\
Poland & & & 0.909 & 0.864 & 0.923 \\
Portugal & & & 0.843 & & 0.898 \\
Slovenia & & & 1.094 & 0.972 & 0.916 \\
South Korea & & & & 0.833 & 0.817 \\
Spain & & & 1.013 & 0.872 & 0.873 \\
Sweden & & 0.996 & 0.964 & 0.938 & 0.927 \\
Switzerland & & & & & 0.828 \\
Turkey & & & & & 0.630 \\
UK & 0.967 & 0.934 & 0.944 & & \\
US & 0.905 & 0.919 & 0.877 & 0.888 & 0.788 \\
\hline
\end{tabular}




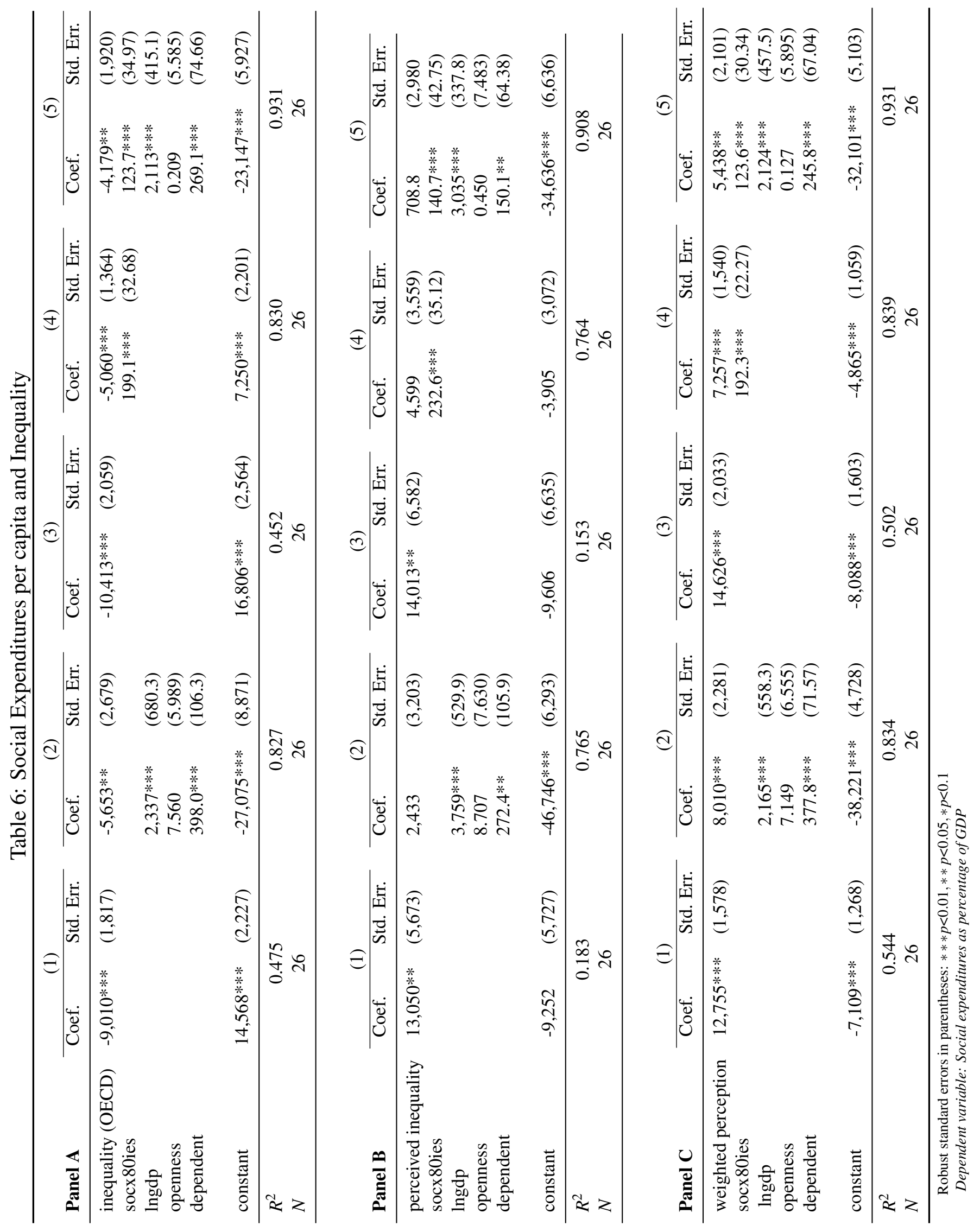




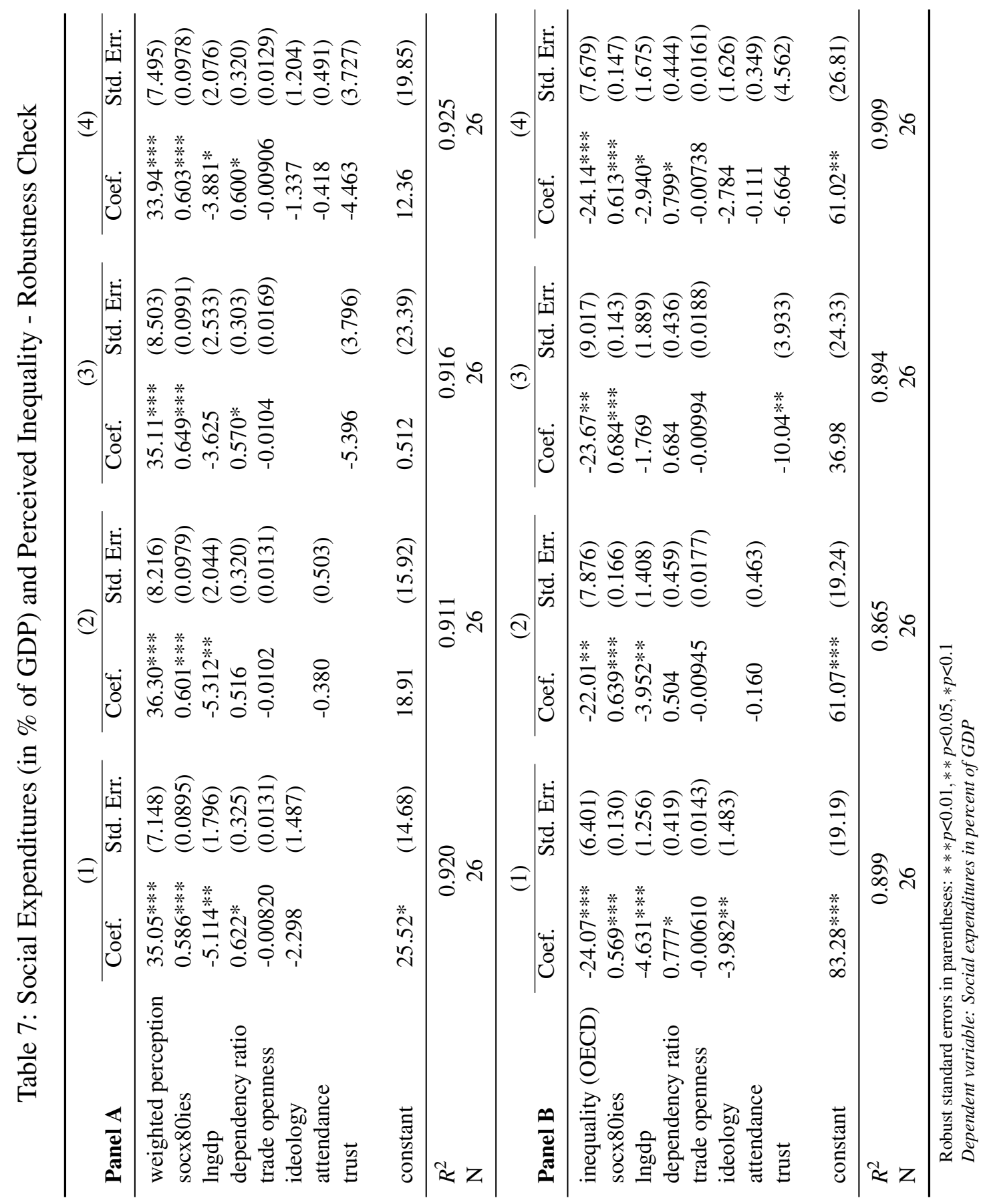




\section{Addenda to Section 4 (POUM Hypothesis)}

Table 8: Upward mobility per year

\begin{tabular}{|c|c|c|c|c|c|c|}
\hline & \multicolumn{2}{|c|}{1992} & \multicolumn{2}{|c|}{1999} & \multicolumn{2}{|c|}{2009} \\
\hline & experienced & perceived & experienced & perceived & experienced & perceived \\
\hline Austria & 0.434 & 0.773 & 0.4293 & 0.631 & 0.444 & 0.759 \\
\hline Canada & 0.537 & 0.823 & 0.466 & 0.658 & & \\
\hline Chile & & & 0.344 & 0.575 & 0.372 & 0.764 \\
\hline Czech Republic & & & 0.382 & 0.460 & 0.343 & 0.816 \\
\hline Denmark & & & & & 0.468 & 0.681 \\
\hline Finland & & & & & 0.482 & 0.744 \\
\hline France & & & 0.574 & 0.533 & 0.531 & 0.725 \\
\hline Germany & 0.457 & 0.725 & 0.383 & 0.666 & & \\
\hline Hungary & 0.448 & 0.719 & 0.445 & 0.422 & 0.341 & 0.798 \\
\hline Italy & 0.578 & 0.706 & & & 0.471 & 0.755 \\
\hline Israel & & & 0.532 & 0.578 & 0.432 & 0.776 \\
\hline Japan & & & 0.202 & 0.638 & 0.222 & 0.768 \\
\hline New Zealand & 0.442 & 0.848 & 0.440 & 0.624 & 0.432 & 0.878 \\
\hline Norway & 0.384 & 0.779 & 0.427 & 0.581 & 0.448 & 0.819 \\
\hline Poland & 0.516 & 0.805 & 0.494 & 0.553 & 0.500 & 0.816 \\
\hline Portugal & & & 0.630 & 0.529 & 0.569 & 0.878 \\
\hline Slovenia & 0.392 & 0.689 & 0.3819 & 0.472 & 0.392 & 0.784 \\
\hline South Korea & & & & & 0.377 & 0.858 \\
\hline Spain & & & 0.574 & 0.579 & 0.472 & 0.772 \\
\hline Sweden & 0.354 & 0.755 & 0.374 & 0.615 & 0.443 & 0.784 \\
\hline Switzerland & & & & & 0.466 & 0.761 \\
\hline Turkey & & & & & 0.353 & 0.798 \\
\hline UK & 0.517 & 0.831 & 0.474 & 0.623 & & \\
\hline US & 0.565 & 0.849 & 0.478 & 0.724 & 0.458 & 0.876 \\
\hline
\end{tabular}

Table 9: Social Expenditures (in \% of GDP) and Perceived Immobility - Robustness Check

\begin{tabular}{|c|c|c|c|c|c|c|}
\hline & \multicolumn{2}{|c|}{ (1) } & \multicolumn{2}{|c|}{ (2) } & \multicolumn{2}{|c|}{ (3) } \\
\hline & Coef. & Std. Err. & Coef. & Std. Err. & Coef. & Std. Err. \\
\hline perceived immobility & 34.61 & (21.27) & $34.23 *$ & (19.27) & $34.84 * *$ & (13.67) \\
\hline socx80ies & $0.795 * * *$ & $(0.118)$ & $0.681 * * *$ & $(0.170)$ & $0.665 * * *$ & $(0.152)$ \\
\hline $\operatorname{lngdp}$ & & & 2.316 & $(2.529)$ & 3.074 & $(3.585)$ \\
\hline openness & & & 0.0302 & $(0.0363)$ & $0.852 *$ & $(0.424)$ \\
\hline dependent & & & 0.418 & $(0.475)$ & 0.0575 & $(0.0341)$ \\
\hline ideology & & & & & -2.921 & $(2.151)$ \\
\hline attendance & & & & & $1.222 *$ & $(0.675)$ \\
\hline trust & & & & & -0.750 & (6.666) \\
\hline constant & $54.63^{* * * *}$ & (15.97) & -31.34 & $(34.95)$ & -43.70 & (39.30) \\
\hline$R^{2}$ & \multicolumn{2}{|c|}{0.825} & \multicolumn{2}{|c|}{0.847} & \multicolumn{2}{|c|}{0.888} \\
\hline$N$ & \multicolumn{2}{|c|}{22} & \multicolumn{2}{|c|}{22} & \multicolumn{2}{|c|}{22} \\
\hline
\end{tabular}

Robust standard errors in parentheses: $* * * p<0.01, * * p<0.05, * p<0.1$

Dependent variable: Social expenditures as percentage of GDP 


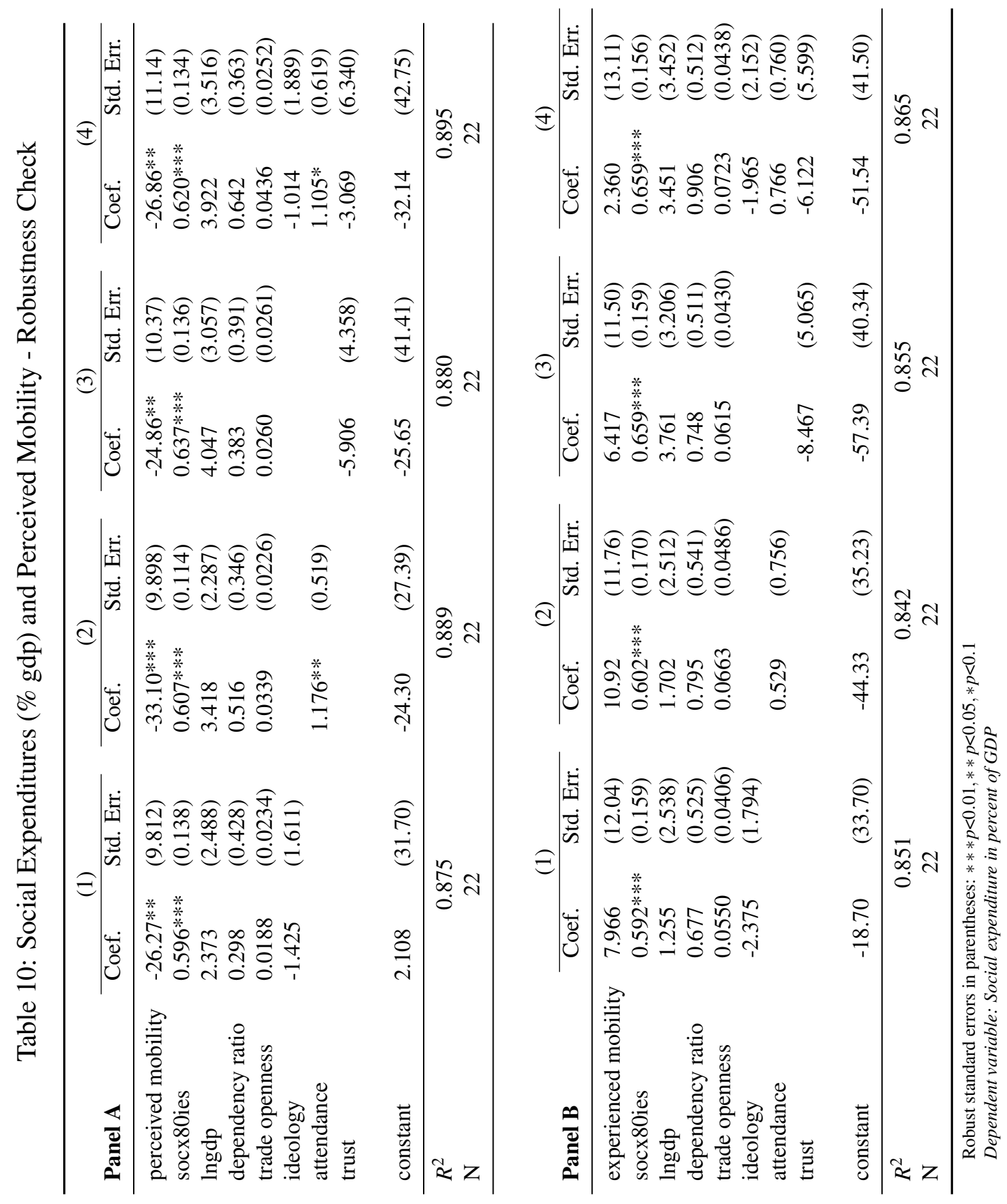

